\title{
Arqueologia Jê no sertão paulista: os Kayapó Meridionais na bacia do Rio Grande - SP
}

Renan Pezzi Rasteiro*

RASTEIRO, R.P. Arqueologia Jê no sertão paulista: os Kayapó Meridionais na bacia do

Rio Grande - SP. R. Museu Arq. Etn., 27: 90-102, 2016

Resumo: Esse artigo apresenta informações relacionadas à arqueologia e etno-história da região norte do estado de São Paulo. A pesquisa concentra-se no contexto da bacia do Rio Grande tendo como foco os grupos indígenas Jê, denominados nos relatos históricos da área pelo etnônimo de Kayapó Meridionais, que ocuparam o território entre os séculos XVII e XX. Os relatos de cronistas, naturalistas, viajantes e exploradores que percorreram a região e produziram vasta documentação em conjunto com os dados arqueológicos fornecem subsídios que contribuem para o debate da inserção dos indígenas na formação da história regional. Por meio do levantamento e da sistematização destas informações busca-se elaborar e fornecer dados sobre esses povos que permitam uma melhor compreensão sobre a ocupação Jê no Brasil, colaborando assim, com as futuras pesquisas arqueológicas na área.

Palavras-chave: Kayapó Meridional; Bacia do Rio Grande; Norte de São Paulo; Arqueologia regional.

\section{Introdução}

\begin{abstract}
Associação direta entre o registro arqueológico dos períodos pré-coloniais e coloniais com a identidade étnica de povos indígenas, conhecidos histórica e etnograficamente, vem sido discutida há um bom tempo dentro da Arqueologia brasileira. Essa tendência aumentou suas proporções, principalmente a partir do advento, nas décadas de 1960 e 1970, do Programa Nacional de Pesquisas Arqueológicas (PRONAPA), sob a coordenação de Clifford Evans e Betty Meggers. Desde então diversas pesquisas têm sido executadas, de diferentes formas, a partir de ideias que unem as abordagens histórico-culturalistas com métodos e
\end{abstract}

(*) Mestre em Arqueologia pelo Programa de Pós-Graduação em Arqueologia do Museu de Arqueologia e Etnologia da USP - MAE/USP.<rpezzir@gmail.com> técnicas vindos das perspectivas processualistas (a partir de 1980) e pós-processualistas (Eremites de Oliveira 2007: 95).

Desses trabalhos produzidos, até então, muitos buscaram através dos dados empíricos uma sistematização que permitisse a elaboração de sínteses regionais, revisão de modelos pré-concebidos e a criação de novos paradigmas interpretativos da cultura material. Para a história indígena o debate interdisciplinar entre Arqueologia, Antropologia e Etno-história tem apresentado resultados muito interessantes.

Porém, um problema decorrente de tais debates tem sido no estabelecimento de relações diretas entre os grupos étnicos com as tradições ceramistas. O problema é que muitas vezes estas associações partem de documentos históricos incompletos produzidos durante o período colonial em diante. Esse fato gera, de maneira recorrente, dados que não consideram as mu- 
danças socioculturais decorrentes dos contatos entre os vários grupos étnicos, e também desses com os colonizadores europeus. Talvez pela maneira que os documentos históricos foram escritos, suscitando leituras homogeneizantes e sincrônicas dos dados etnográficos e históricos, produzidos ao longo deste período, dificultando a visibilidade dos intercâmbios culturais que ocorriam entre estes povos.

Um dos grandes expoentes dessas analogias, no Brasil, foi Brochado. Na sua tese de doutorado (Brochado 1984) propôs a Arqueologia como uma forma de compreender a história indígena, de modo que as trajetórias dos povos ceramistas pré-coloniais deveriam ser identificadas pelas categorias classificatórias da Arqueologia, para melhor se entender a continuidade histórica e cultural dos grupos estudados. Com isso se apontariam as continuidades ou permanências, e as descontinuidades ou mudanças culturais, formando novos modelos para a interpretação arqueológica.

Contudo, como aponta Eremites de Oliveira (2007), essa proposta apresenta um problema na atualidade, pois estimula o uso deliberado da analogia histórica direta entre os grupos ceramistas pré-coloniais e os povos indígenas atuais conhecidos pela Etnologia, desconsiderando a dinamicidade desses grupos. Muitos dos modelos apresentados, até então, desconsideram a auto identificação desses povos e a maneira como estes se organizam e se diferenciam.

No caso da região do Rio Grande, o termo "Cayapó" tem sido usado desde os tempos coloniais para se referir aos grupos Jê de maneira genérica. Associando-os com a categoria classificatória Tradição Aratu, temos a construção de uma imagem globalizante desses povos que acabam sendo fossilizados ao longo do tempo. Evidentemente o que se passa é que, no período em que essas interpretações foram realizadas, os arqueólogos estavam trabalhando com uma quantidade de dados arqueológicos menores que, atualmente, aumentaram principalmente por conta dos trabalhos arqueológicos ligados com as novas leis ambientais que inseriram a arqueologia nos processos de licenciamento ambiental.
Em busca de novos paradigmas que contribuam para a compreensão dos povos indígenas brasileiros, algumas linhas da Arqueologia passaram a utilizar os dados arqueológicos em conjunção aos documentos históricos e os relatos orais locais, na tentativa de projetar, de maneira mais clara, a realidade vivida pelos povos indígenas de determinada região.

Com base nessa perspectiva a presente pesquisa levantou e sistematizou os dados arqueológicos e históricos disponíveis no intuito de contribuir para o avanço das pesquisas arqueológicas sistemáticas no contexto do estado de São Paulo, tendo como foco os grupos indígenas pertencentes aos falantes da família linguística Jê, do tronco Macro-Jê, denominados nos documentos históricos regionais pelo etnônimo Kayapó Meridionais.

A área analisada abarca parte da Bacia do Rio Grande, mais especificamente o Baixo-Grande. O trecho considerado parte da confluência do Rio Canoas onde se iniciam as divisas dos estados de São Paulo e Minas Gerais, até a junção do Rio Grande com o Rio Paranaíba formando o Rio Paraná. Na região paulista, foco deste artigo, a área compreende três unidades de Recursos Hídricos sendo elas a bacia do Turvo-Grande (UGRHI 15), a bacia do Baixo-Pardo/Grande (UGRHI 12) e a bacia Sapucai-Grande (UGRHI 8), em uma área de cerca de 100 municípios (fig. 1).

A região trabalhada também abarca uma parte do Triângulo Mineiro, mais especificamente a bacia do Baixo-Grande (GD8), contando com cerca de 20 municípios no estado mineiro. Porém esse artigo concentra-se apenas no levantamento realizado na margem paulista do Rio Grande ${ }^{1}$.

\section{História indígena no Rio Grande}

As incursões sertanistas provindas de São Paulo datam do início do século XVII e vão até o século XVIII, estas se caracterizavam pelo aprisionamento de índios e a busca de metais

1 Para mais informações ver Rasteiro (2015). 


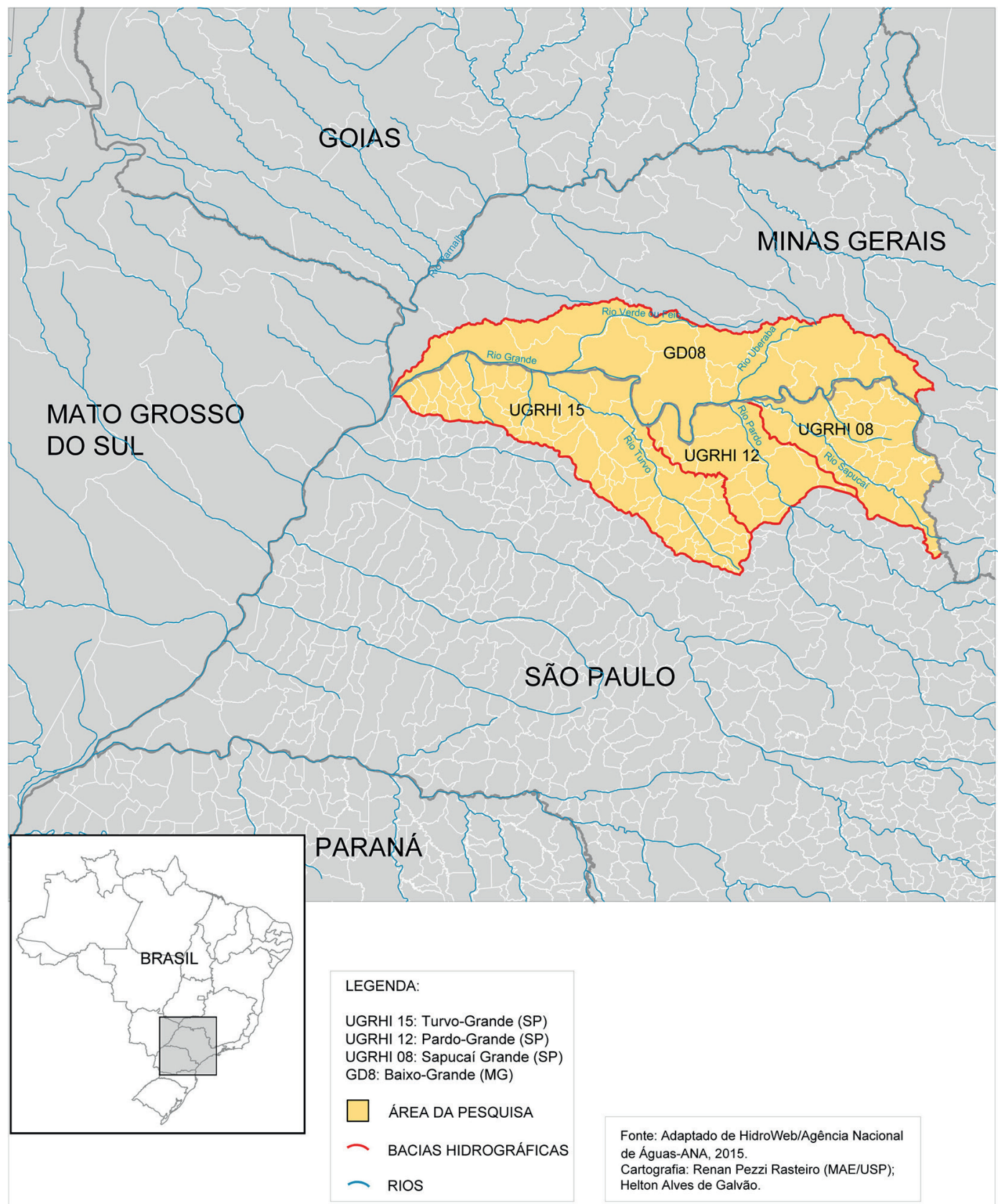

Fig. 1. Área da Pesquisa (Rasteiro 2015)

preciosos. Nos documentos da época eram tratadas como entrada, jornada, viagem ou descobrimento (Taunay 1929: 115).

Durante o século XVII, colonos de São Paulo assaltaram inúmeras aldeias indígenas em diversas regiões da Capitania, trazendo grande número de índios como cativos e os colocando para trabalhar em suas lavouras na condição de "serviço obrigatório". Com isso houve um visível aumento na mão-de-obra indígena no pla- 
nalto paulista, o que por sua vez foi a engrenagem que possibilitou o desenvolvimento de um circuito mercantil interno do país, fazendo com que São Paulo interagisse com outras regiões da colônia. No geral pode-se dizer que o "bandeirismo" sempre teve o mesmo motivo fundamental: a necessidade crônica de mão-de-obra indígena para a manutenção da agricultura paulista (Monteiro 1994: 57).

No entanto, ao longo dos séculos as condições de apresamento desses grupos foram se alterando, devido principalmente às condições geográficas, às distâncias percorridas, às reações dos indígenas abordados e aos custos das expedições. Pode-se afirmar que até a primeira metade do século XVII, a Capitania de São Paulo preencheu suas necessidades de mão-de-obra cativa com grandes levas de índios guarani, contudo esse abastecimento é bruscamente interrompido nos anos de 1640. Essa interrupção no fornecimento de cativos repercutiu gravemente na estrutura econômica local. Diante de tal situação, os colonos tiveram que desenvolver novas estratégias de apresamento de indígenas. $\mathrm{Na}$ medida em que os escambos e assaltos do século XVI e início do XVII se deram nas imediações do Rio Tietê, agora as expedições teriam que se projetar mais além, ligando-se às emergentes rotas comerciais entre as capitanias.

Com a descoberta das minas de Goiás e Cuiabá em meados da segunda década do século XVIII, várias bandeiras partiram rumo ao Planalto Central em busca de riquezas. A ordem das autoridades visava à incorporação do indígena à sociedade colonial através de aldeamentos onde estes trabalhariam na agricultura e mineração, porém se houvesse alguma resistência por parte destes, a resolução seria a escravização ou extermínio desses povos (Kok 2004: 142).

Nesse contexto tem início a guerra de extermínio sobre o comando de Rodrigo César de Menezes, que em testemunho alega ter enviado tropas contra os Kayapó afirmando ainda: "e eles resistindo com tanta força e valor que só depois de verem mortos quarenta e tantos dos seus se renderam" (Kok 2004: 144). Em consequência aos efeitos desse estado de guerra, surge a resistência Kayapó, que viria a durar por quase meio século.
Os diversos relatos para esse período apresentam episódios intensos de conflito entre os indígenas e os colonos, fornecendo ao governo as ferramentas ideais para a criação de um modelo de barbárie e selvageria, que justificariam a colonização da região.

Entre as descrições dos Kayapó, dessa época, se destacam aquelas que os apontam como índios traiçoeiros e cruéis como as citadas por Kok:

\footnotetext{
"Ao referir-se aos caiapós, D. Antônio Rolim e Moura observa que o seu modo de lutar "é atraiçoadamente". Da perspectiva do Capitão João Antônio Cabral Camelo, "é o mais traidor de todos", a mesma opinião que se repetiria, alguns anos depois, no relato "Divertimento admirável": "os mais cruéis, indômitos e traidores" (Kok 2004: 143).
}

Localizados nas margens dos rios Pardo (MT), Taquari (MS), Paraná (SP/MS), Claro (MS), Coxim (MS), Camapuã (MS) e Grande (MG/SP), os Kayapó atacavam fazendas e arraiais, barcos, lavouras, minas, queimando roças, matando qualquer não-índio, inclusive escravos, que entrassem em seu caminho.

Com o passar do tempo e continuidade dos conflitos, várias reuniões foram organizadas com o fim de criação de táticas para extermínio dos Kayapó. Dessa forma apelou-se para a contratação de sertanistas que possuíam em sua companhia índios catequizados.

Dessa maneira, em 1741, Antônio Pires de Campos, ícone da política de aprisionamento indígena, juntamente com cerca de 450 guerreiros Bororo, partem contra os Kayapó eliminando em massa várias aldeias desses povos. No mesmo ano sua tropa atravessa o Paranaíba e constrói uma aldeia próxima ao ribeirão das Pedras para abrigar o seu exército. Porém a resistência dos Kayapó Meridionais demonstrava, cada vez mais, que não iria abandonar o seu território tão facilmente.

Em 1742 o então governador geral da Capitania de São Paulo, d. Luiz de Mascarenhas, instrui aos sertanistas: "[...] não se rendendo os ditos Gentios, e sendo tomada as mãos na pelleja os passarão a espada sem distinção ou differença algûa de sexo, só não executarão a da. pena de morte nos 
meninos e meninas de dês annos pa. baixo, porque estes os conduzirão a esta Va. para delles se tirar o quinto de S. Mage. E os mais se repartirem por quem tocar" (Documentos Interessantes 1896: 168).

Alguns anos mais tarde, em 1748, Antônio Pires de Campos recebe a solicitação de criar novo aldeamento nas margens da estrada de São Paulo - Goiás. Com isso ele ganha o título de Coronel da Conquista do Gentio Kayapó do Sul, além da tensa de cinquenta mil réis e o hábito de Cristo que seria sua recompensa ao término da derrota completa da nação Kayapó (Ataídes 1998: 74). Apesar da grande investida dessa segunda campanha, os Kayapó ainda ganhavam boa parte das batalhas.

A problemática da guerra perdurou até meados da década de 1770, quando os governadores começam a implantar ideias mais liberais, devido à própria exaustão das forças de ambos os lados.

Em razão da própria sobrevivência do grupo, os Kayapó começam a se estabelecer pacificamente em aldeamentos, como o de São José de Mossâmedes e o Maria I.

Após o esgotamento das jazidas, os indivíduos que se ocupavam dessa atividade começaram a se deslocar em busca de novas terras, dando início à fase de ruralização da colônia brasileira. Isso marcou uma etapa de expulsão dos remanescentes Kayapó, em prol de uma política agropecuarista.

Segundo o padre Luiz Antônio Silva e Souza, em 1812, recolhendo os relatos orais na região, concluiu haver pelo menos três grandes aldeamentos próximos a rios de maior porte, sendo esses: o aldeamento do Rio das Pedras (hoje Cascalho Rico-MG), o de Santana (hoje Indianópolis-MG) e o de Lanhoso (sem informação). Porém, Aires de Casal (1976) escreve que a aldeia de Lanhoso surge em 1775, quando os índios Bororo da aldeia de Santana são transferidos para as proximidades do Rio Grande, para dar lugar aos Xacriabá trazidos pelo governo goiano. Em 1816, Eschwege (1996) visitou nove aldeamentos instalados no trajeto da estrada que, segundo sugere Lourenço (2005), devem ter nascido do desmembramento dos aldeamentos originais citados pelo padre Luiz Antônio Silva e Souza (Lourenço 2005: 56).
Tomando como base os relatos de Saint-Hilaire, D’Alincourt e Eschwege, carregados de descrições hidrográficas e paisagísticas, e com o auxilio de cartas topográficas, Lourenço (2005) produziu um mapa com a posição aproximada dos aldeamentos do Sertão da Farinha Podre (como era conhecida a região), no início do século XIX (Lourenço 2005: 57). A configuração da área pode ser vista na figura 2 .

Os aldeamentos têm vida curta na região. Seja por conta do trabalho forçado ou das epidemias que constantemente assolavam os aldeamentos, os Kayapó fugiram em massa. Em 1846 documentos já afirmavam que o aldeamento de São José de Mossâmedes estava vazio, sendo declarado extinto oficialmente em 1879 (Giraldin 2000: 13).

Com esse total fracasso dos aldeamentos, o que ocorre é uma nova onda de conflito entre os Kayapó e a comunidade de não-índios, que começam a ser resolvidos em disputas sem a participação das autoridades.

Como consequência de todos esses fatos, e tendo em mente o espírito positivista do começo do século XX, que via como evidente a extinção de povos em fases "inferiores", os Kayapó foram dados como extintos. Isso fica claro no relato do etnógrafo Curt Nimuendajú à Superintendência de Proteção ao Índio (SPI), ao descrever, em 1910, um grupo Kayapó com pouco mais de 30 pessoas localizado na margem mineira do Rio Grande: "Hoje os Kaiapó Meridionais desapareceram como tribo" (Nimuendajú 1952: 427). Robert Lowie (1946: 519) concorda com essa afirmação, no seu texto no Handbook of South American Indians, na parte referente aos Kayapó, utilizando como fonte os relatos de Saint-Hilaire e Pohl, afirma que aquela "tribo" deixou de existir. Egon Schaden, grande etnólogo, em 1954, compartilha da mesma hipótese afirmando a extinção do grupo (Schaden 1954: 397).

Porém recentes pesquisas de linguistas e historiadores têm apontado para a não extinção dos Kayapó Meridionais, sendo a etnia Kren-Akarore ou Panará, localizados no Mato Grosso, possíveis remanescente desses grupos Jê (Giraldin 1994, 2000).

Fato é que a presença marcante desses povos e a belicosidade dos mesmos condiciona- 


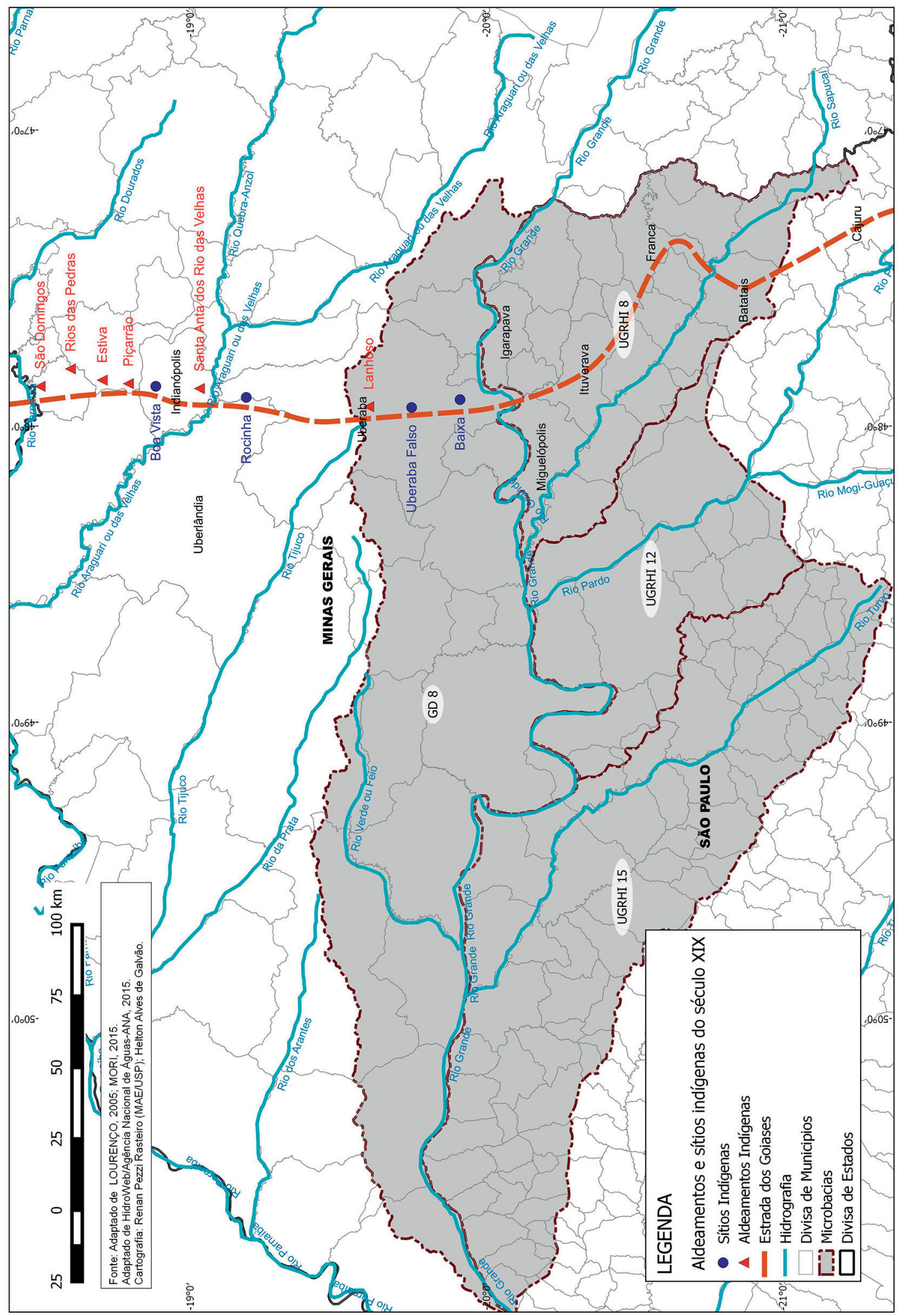

Fig. 2. Mapa dos aldeamentos e sítios indígenas na região do Baixo-Grande, século XIX (Rasteiro 2015). 
ram por todos os séculos XVII e XVIII o acesso luso-brasileiro às minas de Mato Grosso e Goiás (Mano 2006), demonstrando ainda mais a importância desses indígenas no processo de formação da história regional.

\section{Contexto arqueológico regional}

De maneira geral, muitos autores defendem a ideia de São Paulo como uma área limite para diversos grupos ceramistas, entretanto ainda há muitas perguntas a serem respondidas, quanto a distribuição geográfica, cronologias e tipos de fronteiras que envolviam esses indivíduos. No passado as pesquisas tinham como preocupação identificar vestígios que pudessem ser associados a alguma das tradições definidas pelo PRONAPA, porém o que tem se visto é a necessidade crescente de entender, através das evidências, como se deram as interações culturais entre esses grupos (Robrahn-González 1996). O aumento de amostragem desse material cerâmico decorrente dos trabalhos de contrato (Zanettini Arqueologia 2007, 2010) e pesquisas acadêmicas recentes (Moraes 2007) têm demonstrado a imensa variabilidade de interações que ocorreram na região. Para Afonso, "Os achados aparentemente "exóticos", que poderiam ser interpretados como enclaves ou intrusões, mostram-se como elementos diagnósticos de uma relação complexa entre grupos diferentes, verdadeiros marcadores da interação cultural. Este passado pré-histórico está se revelando cada vez mais complexo e ao mesmo tempo mais interessante e provocativo" (Afonso 2009: 04).

Robrahn-González (2001) coloca em questão a diversidade das indústrias cerâmicas do estado de São Paulo, através de cerca de 200 sítios conhecidos até então. A autora indica três grandes unidades classificatórias para o estado, sendo elas as Tradições Tupiguarani, Itararé e Aratu-Sapucaí. A primeira seria uma ocupação mais antiga e se distribuiria em todo estado, a segunda se concentraria na região sul e a terceira na região norte do estado, sendo essa última o foco de nossa pesquisa.

A tradição arqueológica Aratu foi definida por Valentin Calderón (1967/1968), em estudo realizado no Distrito de Aratu, localizado na
Baía de Todos os Santos, sendo caracterizada inicialmente pelas inúmeras urnas funerárias piriformes. As pesquisas de Calderón (1969/1970) consolidaram essa tradição ao localizar outros sítios no estado baiano, sendo 14 sítios no litoral norte e 12 na região ocidental do estado.

A cerâmica Aratu se distingue pela não decoração, a utilização de antiplástico mineral, vasilhas piriformes, vasos geminados, tigelas e bordas onduladas. André Prous (1992) ressalta, no entanto, a influência Tupiguarani em algumas regiões, notavelmente no litoral capixaba, onde algumas dessas vasilhas apresentam engobo, e decorações plásticas e pintadas.

Acerca da decoração na cerâmica Aratu, em um texto publicado por Jorge Eremites de Oliveira e Sibele Viana, intitulado a "Pré-História da região Centro-Oeste do Brasil” (1999/2000), os autores já destacam o elemento decorativo não associado à influência Tupiguarani. "Na Tradição Aratu, grande parte dos recipientes é maior que os dos grupos anteriormente tratados. Foram confeccionadas vasilhas piriformes, esféricas ou elipsoides grandes. As bordas dos recipientes não apresentam reforço e as bases apresentavam-se arredondadas, côncavas ou furadas. São comuns as formas grandes que comportam de dezenas a centenas de litros, embora sejam quase inexistentes os grandes pratos ou assadores. Uma outra forma característica é um pequeno vasilhame geminado. Destacam-se ainda rodelas de fuso, carimbos e cachimbos tubulares. As decorações são poucas: inciso, entalhe, ungulado, ponteado, borda acastelada, asa, aplique mamilonar, banho vermelho e pintura preta. O antiplástico predominante é 0 mineral, que é substituído gradualmente pelo cariapé (Schmitz 1976-1977; Schmitz e Barbosa 1985).

Segundo Mello et al. (1996), esta relação temporal não está presente em toda a região Centro-Oeste, de modo que os aditivos cerâmicos devem ser utilizados com cautela na pesquisa arqueológica, podendo contribuir ocasionalmente para a identificação de grupos culturais, mas não necessariamente serem utilizados como parâmetro cronológico" (Eremites de Oliveira e Viana 1999-2000: 164).

Já a Tradição Sapucaí foi definida por Dias Júnior, no estado de Minas Gerais, junto ao Rio Grande, caracterizando essa cerâmica a presença de vasos grandes de paredes grossas, diferindo suas formas de piriformes para globulares. 
Apresenta por vezes o banho vermelho, e vasos menores com paredes finas perfuradas na lateral (Prous 1992: 351).

Diversos autores propõem a união dessas duas tradições, o que de fato faz sentido, pois as duas apresentam muitas semelhanças, como por exemplo, a não utilização de pratos assadores de mandioca (Robrahn-González 1996).

Entre as fases, se destaca para nosso estudo a fase Mossâmedes. Identificada por Schmitz entre as décadas de 1970 e 1980, no estado de Goiás, apresenta características comuns básicas das tradições Aratu e Sapucaí, porém expõe traços que indicam a influência da Tradição Uru do Brasil Central, como a utilização do antiplástico vegetal (cariapé), bases planas de $90^{\circ}$ e grandes pratos possivelmente utilizados no preparo da mandioca (Schmitz et al. 1982).

A morfologia desses sítios da tradição Aratu-Sapucaí se assemelha às grandes aldeias Jê do Brasil Central, sendo formadas por casas dispostas em círculo ao redor de uma grande praça central, eventualmente com duas ou mais linhas concêntricas.

Para a linguística, segundo Greg Urban (1992), o local onde teriam se originado os povos Jê estaria em algum lugar entre as nascentes do Araguaia e do São Francisco, próximo à área onde os Xacriabá habitavam. A partir desse ponto teriam ocorridos duas grandes cisões: uma há 3 mil anos onde os Jê meridionais teriam migrado para o sul e outra em torno de 1 e 2 mil anos entre os ramos central e setentrional, onde estes últimos teriam se dirigido à bacia amazônica e gradualmente para oeste (Urban 1992: 90).

É interessante ressaltar, também, a origem dos grupos Jê contada a partir da tradição oral de alguns desses povos, como relata Giannini (1991), ao descrever um mito dos Kayapó -Xikrin. "Todos os grupos kayapó autodenominam-se mebengokré, ou seja, "gente do buraco d'água" ou "gente da água grande", referindo-se aos rios Tocantins e Araguaia, cuja travessia foi supostamente a separação do grupo ancestral. As tradições orais kayapó remetem à diferenciação dos povos Jê como tendo ocorrido na área entre os rios Araguaia e Tocantins, no atual estado do Tocantins. Segundo o mito, os ancestrais dos Jê viviam juntos como um só grupo nessa área até descobrirem uma grande árvore de milho, mas, à medida que recolhiam as sementes, começaram a falar linguas diferentes e se separaram nos diversos grupos jê atuais" (Giannini 1991).

Duas linhas interpretativas sobre a origem desses povos Jê predominam na Arqueologia, sendo que ambas voltadas para o Brasil Central, local onde houve mais pesquisas relacionadas à Tradição Aratu. A primeira linha defende a ideia de que os grupos Jê e Cariri teriam vindos da Amazônia em levas migratórias ocasionadas por diversos motivos possíveis como mudanças ambientais, expansão, aumentos populacionais, entre outros (Brochado 1984). Dessa forma teríamos as populações do tronco Macro-Jê como os portadores da cerâmica Aratu. Na segunda linha a ideia é de que essas grandes aldeias do Brasil Central sofreram processos históricos específicos, ocorridos no Centro Oeste, que as levaram a se diferenciar na produção cerâmica (Wüst e Barreto 1999).

Para Robrahn-González (1996, 2001), uma hipótese de origem dos grupos seria uma combinação de fatores internos e externos dessas comunidades, ressaltando que o desenvolvimento das mesmas pode ter derivado tanto de processos locais, quanto de deslocamentos externos, envolvendo diferentes formas de contato cultural.

Quando voltamos nossa atenção aos sítios associados à Tradição Aratu-Sapucaí na região norte do estado de São Paulo, a discussão se torna ainda mais complexa, por conta da variabilidade cerâmica e das interações culturais entre esses grupos Jê e desses com os Tupi. Isso fica claro nas observações de Pereira Jr sobre seus dados coletados na região de Franca. "Devemos fazer notar, entretanto, que em dados casos, entre restos abundantes dessa cerâmica preciosa tida como de origem tupi-guarani, ocorre um ou outro fragmento de material que, pela sua apresentação sugere origem diferente, enquanto em outros locais ocorre o contrário, ou seja, o encontro dessa cerâmica melhor entre os restos de outra mais grosseira acentuadamente diversa" (Pereira Jr 1957: 314).

Interessante ressaltar que apesar de notarmos a influência Uru na cerâmica Aratu nesses contextos, não podemos associá-las à fase Mossâmedes descrita por Schmitz et al. (1982), pois 
aqui ao contrário existe uma grande variação nas formas e também não foram encontrados pratos assadores, típicos da Uru, como sugere o autor.

Nesse contexto arqueológico regional, o que se observa é que as categorias analíticas não têm dado conta da problemática que vem sendo evidenciada. Tendo esse dado em vista, conjuntamente com os documentos históricos acerca dos Kayapó Meridionais, é possível fazer certas ligações etno-históricas e propor outras maneiras de compreensão desses grupos Jê da Bacia do Rio Grande.

Com isso, o quadro que vem se formando para a região aponta um intenso e contínuo fluxo de grupos que perpassa quaisquer hipóteses de homogeneidade desses povos. Essas interações provam que, cada vez mais, esses grupos Jê e Tupi produziram uma gama de vestígios diferentes de qualquer outro contexto regional, evidenciando ainda mais a necessidade de uma síntese sobre a ocupação indígena na bacia do Rio Grande.

\section{Dados arqueológicos levantados}

A coleta de dados teve início no ano de 2012, através do levantamento bibliográfico teórico e das documentações históricas sobre os povos Jê da região. De fato essa pesquisa histórica já havia sido bem tratada por diversos autores (Neme 1969; Giraldin 1994; Ataídes 1998; Kok 2004; Lourenço 2005; Mori 2015). Este trabalho, portanto, focou-se em organizar os dados da melhor maneira possivel.

Em 2013, foi realizado o levantamentos no arquivo da Superintendência Regional do IPHAN de São Paulo, onde foram reunidas as fichas de cadastro de sítios dos munícipios da região da pesquisa. A análise das fichas de cadastro de sítios arqueológicos revelou que estas apresentam muitas lacunas.

Ao final da coleta foram identificados 293 sítios arqueológicos cadastrados na área que abarca 118 municípios, dos quais 99 destes se localizam no estado de São Paulo.

Dentro das bacias paulistas pesquisadas, a Bacia do Pardo-Grande (UGRHI 12) apresentou 46 sítios, a Bacia do Turvo-Grande (UGRHI 15) apresentou 71 sítios e a bacia do Sapucaí-Grande (UGRHI 8) apresentou 87 sítios cadastrados.

Considerando o total de sítios levantados pela pesquisa, os tipos de sítios registrados na região variam de maneira significante. A maioria dos sítios cadastrados, cerca de 107 sítios, são do tipo cerâmico, 99 lito-cerâmicos, 62 líticos, 16 históricos, 2 de arte rupestre, 1 multicomponencial e 6 sem informação, totalizando os 293 sítios cadastrados.

Do total de 293 sítios, 206 se caracterizam como sítios cerâmicos ou lito-cerâmicos, foco da presente pesquisa, porém, apenas 170 apresentaram coordenadas geográficas válidas, cerca de $82 \%$ do total de sítios ceramistas. Como o principal interesse dessa pesquisa se volta para os povos Jê da bacia do rio Grande, a prioridade na análise das fichas do Cadastro Nacional de Sítios Arqueológicos (CNSA) foi identificar quais destes sítios poderiam indicar alguma relação com esses grupos.

Cerca de 49 sítios ceramistas dos 206 foram classificados dentro da categoria Aratu, enquanto 10 estão associados à Tradição Tupiguarani e 1 sítio classificado como Tradição Uru. Outros sítios foram cadastrados com duas tradições ceramistas, sendo que 6 destes apresentam características Aratu e Uru e 2 características Aratu e Tupi. O restante dos sítios não possui nenhuma categoria classificatória aparente, simplesmente foram identificados.

O levantamento na margem paulista apresentou um total de 152 sítios cerâmicos ou litocerâmicos, sendo que 26 destes não possuíam coordenadas geográficas. Destes sítios 25 foram considerados pertencentes à Tradição Aratu, 9 à Tradição Tupi, 1 à Tradição Uru, 2 Aratu/Tupi e 6 Aratu/Uru (fig. 3).

Os vestígios cerâmicos da Bacia do Rio Grande apresentam uma variabilidade muito grande em comparação com Goiás e outros estados. As formas dos sítios não têm sido bem definidas nos relatórios de Arqueologia Preventiva, isso se dá inclusive por conta da agricultura intensiva da região, o que dificulta as comparações com os dados etnográficos. Poucos são os trabalhos acadêmicos sistemáticos na região que permitam alguma hipótese maior. A distribuição dos diversos sítios arqueológicos na bacia do 


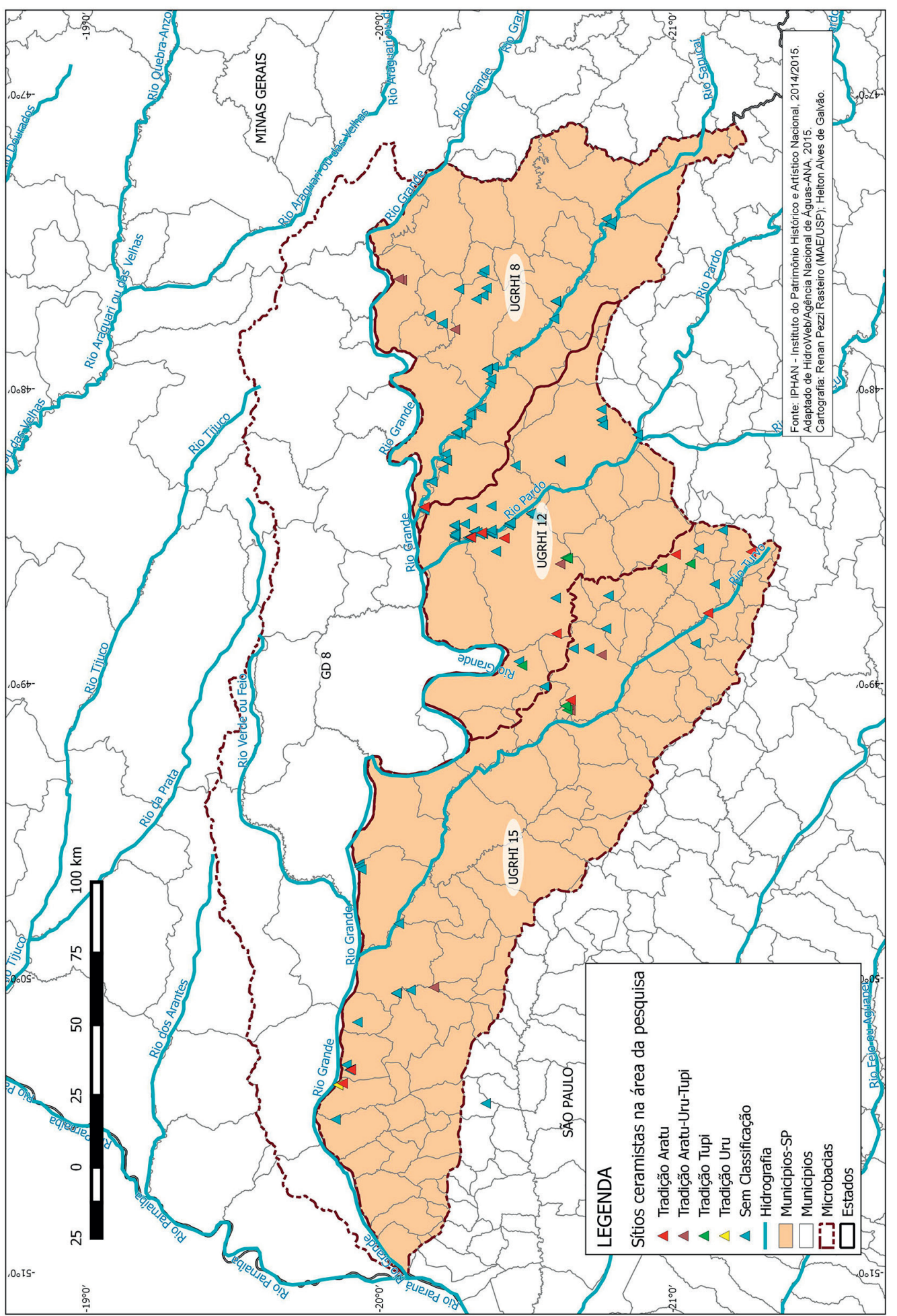

Fig. 3. Mapa dos sítios arqueológicos cerâmicos/lito-cerâmicos cadastrados no IPHAN/SP, na área pesquisada (Rasteiro 2015). 
Rio Grande evidencia amplas áreas sem informação. Essas lacunas não significam a falta de uma ocupação indígena, mas sim a ausência de estudos sistemáticos na região.

\section{Considerações Finais}

Com base nos dados arqueológicos evidenciados, em conjunto com os documentos históricos acerca dos Kayapó Meridionais, uma síntese da história da ocupação dos grupos Jê na Bacia do Rio Grande pode começar a tomar forma.

Com o registro arqueológico revelado, em conjunto com os documentos históricos acerca dos Kayapó Meridionais, pode-se identificar alguns elementos de semelhança que definiram esses grupos e que, consequentemente, os articulou dentro de uma filiação arqueológica denominada Tradição Aratu. Isso provavelmente deve estar relacionado a eventos migratórios e processos de trocas constantes entre esses grupos indígenas.

Porém, ao pensar nesses Kayapó Meridionais dentro de uma diversidade étnica dos grupo Jê, diferentes entre si, acompanhando os estudos etnológicos atuais que demonstram a complexidade organizacional de cada grupo, deve-se apontar a necessidade de mais estudos arqueológicos sistemáticos na região, a partir de análises mais detalhadas, que permitam o avanço do entendimento das particularidades locais e regionais desses povos Jê.

\section{Agradecimentos}

Essa comunicação faz parte de um levantamento maior realizado no âmbito da dissertação de mestrado intitulada "Arqueologia dos Jê da Bacia do Rio Grande: história indígena no norte de São Paulo e no Triângulo Mineiro", defendida no Programa de Pós-graduação em Arqueologia do Museu de Arqueologia e Etnologia da Universidade de São Paulo, no ano de 2015, pelo autor desse artigo. Agradeço, portanto, ao CNPq pela concessão da Bolsa de Mestrado junto ao Programa de Pós-Graduação em Arqueologia do Museu de Arqueologia e Etnologia da USP, que muito auxiliou na realização desta pesquisa. E a minha orientadora Profa. Dra ${ }^{a}$. Marisa Coutinho Afonso que sempre esteve presente para contribuir com o desenvolvimento deste trabalho.

RASTEIRO, R.P. Jê Archaeology in São Paulo's hinterland: the Southern Kayapó in the Rio Grande Basin - SP. R. Museu Arq. Etn., 27: 90-102, 2016

\begin{abstract}
This article presents data on the archaeology and ethnohistory of the northern region of the state of São Paulo. The research concentrates on the context of the Rio Grande basin focusing on indigenous groups Jê, called in historical records of the area as Southern Kayapó who occupied the territory between the seventeenth and twentieth centuries. The reports from chroniclers, naturalists, travelers and explorers who traveled through the region and produced extensive documentation in conjunction with the archaeological research data, contribute to the integration of indigenous groups on the formation of regional history. Through the review and systematization of the informations we develop and provide data about these people to support a better understanding of the Jê occupation in Brazil, thus collaborating with future archaeological researches in the area.
\end{abstract}

Keywords: Southern Kayapó; Rio Grande Basin; North of São Paulo; Regional archaeology. 


\section{Referências Bibliográficas}

Afonso, M.C. 2009. Um painel da Arqueologia pré-histórica no Estado de São Paulo: os sítios cerâmicos. Especiaria - Cadernos de Ciências Humanas 11 (20 e 21):127-155.

Ataídes, J.M. 1998. Sob o signo da violência: colonizadores e Kayapó do Sul no Brasil Central. Editora da Universidade Católica de Goiás, Goiânia.

Brochado, J.J.P. 1984. An ecological model of the spread of pottery and Agriculture into Eastern South America. Thesis PhD. University of Ilinois at Urbana-Champaign, UrbanaChampaign.

Calderón, V.A. 1967/1968. A fase Aratu no Recôncavo e litoral norte do Estado da Bahia. PRONAPA n.3, Publicações Avulsas 13, Museu Paraense Emílio Goeldi, Belém.

Calderón, V.A. 1969/1970. Contribuição para o conhecimento da Arqueologia do Recôncavo e do sul do Estado da Bahia. PRONAPA n.5, Publicações Avulsas 26, Museu Paraense Emílio Goeldi, Belém.

Casal, M.A. 1976. Corografia brasilica ou relações histórico-geográfica do Reino do Brasil. Belo Horizonte, Ed. Itatiaia; São Paulo, Editora da Universidade de São Paulo.

Documentos Interessantes para a História e Costumes de São Paulo, Vol. XXII. 1896. Arquivo do Estado de São Paulo. Typographia da Companhia Industrial de São Paulo, São Paulo.

Eremites de Oliveira, J. 2007. Cultura material e identidade étnica na Arqueologia brasileira: um estudo por ocasião da discussão sobre tradicionalidade da ocupação Kaiowá da terra indigena Sucuri'y. Revista Sociedade e Cultura 10 (1): 95-113.

Eremites de Oliveira, J., Viana, S.A. 1999/2000. O Centro-Oeste antes de Cabral. Revista da USP 44: 142-189.
Eschwege, W.L.v. 1996. Brasil, novo mundo. Domício de Figueiredo Murta (Trad). Centro de Estudos Históricos e Culturais. Fundação João Pinheiro, Belo Horizonte.

Giannini, I.V. 1991. A ave resgatada: "A impossibilidade da leveza do ser". Dissertação de mestrado. Universidade de São Paulo, São Paulo.

Giraldin, O. 1994. Cayapó e Panara: Luta e sobrevivência de um povo. Dissertação de mestrado. Universidade Estadual de Campinas, Campinas.

Giraldin, O. 2000. Renascendo das cinzas: Um histórico da presença Cayapó-Panará em Goiás e no Triângulo Mineiro. Sociedade e Cultura. Revista de Ciências Sociais 3: 1-23.

Kok, G.P. 2004. O sertão itinerante: expedições da capitania de São Paulo no século XVIII. Hucitec Fapesp, São Paulo.

Lourenço, L.A.B. 2005. A oeste das Minas: índios, escravos e homens livres numa fronteira oitocentista. Edufu, Uberlândia/MG.

Lowie, R.H. 1946. The Southern Cayapó. In: Steward, J. H. (Ed.) Handbook of South American Indians, Vol. 1: The marginal tribes. Smithsonian Institution, Bureau of American Ethnology, Bulletin 143. Washington Government Publishing Office, 519-540.

Mano, M. 2006. Os campos de Araraquara: um estudo de História indígena no interior paulista. Tese de doutorado. Universidade Estadual de Campinas, Campinas.

Monteiro, J.M. 1994. Negros da Terra: indios e bandeirantes nas origens da São Paulo. Ed. Companhia das Letras, São Paulo.

Moraes, C.A. 2007. Arqueologia Tupi no Nordeste do Estado de São Paulo: Um estudo de variabi- 
lidade artefatual. Dissertação de mestrado. Universidade de São Paulo, São Paulo.

Mori, R. 2015. Os Aldeamentos Indígenas no Caminho dos Goiases: Guerra, Etnogênese e Identidade no "Sertão do Gentio Cayapó" (Sertão da Farinha Podre). Goiás (1748 - 1816) e Minas Gerais (1816 - 1840). Dissertação de mestrado. Universidade Federal de Uberlândia, Uberlândia.

Neme, M. 1969. Dados para a História dos índios Caiapós. Anais do Museu Paulista 23: 101-147.

Nimuendáju, C. 1952. Os Gorotire. Revista do Museu Paulista. Nova Série VI: 427-453.

Pereira Jr., J.A. 1957. Contribuição para o estudo da Arqueologia do extremo norte paulista. Revista do Instituto Histórico e Geográfico de São Paulo 54: 313-357.

Prous, A. 1992. Arqueologia Brasileira. Ed. UNB, Brasília.

Rasteiro, R.P. 2015. Arqueologia dos Jê da Bacia do Rio Grande: história indígena no norte de São Paulo e no Triângulo Mineiro. Dissertação de mestrado. Universidade de São Paulo, São Paulo.

Robrahn-González, E.M. 1996. Os grupos ceramistas pré-coloniais do Centro-Oeste brasileiro. Revista do Museu de Arqueologia e Etnologia 6: 83-121.

Robrahn-González, E.M. 2001. As aldeias circulares do Brasil Central. In: Museu de
Arqueologia e Etnologia, Brasil 50 mil anos: uma viagem ao passado pré-colonial. Museu de Arqueologia e Etnologia/USP: 35-43.

Schaden, E. 1954. Os primitivos habitantes do território paulista. Revista de História. USP, Separata do n. 18: 396-411.

Schmitz, P.I., Wüst, I., Copé, S.M., Thies, U.M.E. 1982. Arqueologia do Centro Sul de Goiás. Uma fronteira de horticultores indígenas no Centro do Brasil. Pesquisas, Antropologia 33: 49-102.

Taunay, A.E. 1929. História Geral das Bandeiras Paulistas. Cantou, São Paulo.

Urban, G. 1992. A História da cultura brasileira segundo as línguas nativas. In: Carneiro da Cunha, M. (Org). História dos indios no Brasil. Cia das Letras, São Paulo, 87-102.

Wüst, I.; Barreto, C. 1999. Ring Villages of Central Brazil: a challenge for Amazonian archaeology. Latin American Antiquity 10 (1): 03-22.

Zanettini Arqueologia. 2007. Programa de Prospecções e Resgate Arqueológico. Área destinada à instalação de planta industrial, Usina Guarani S/A - Unidade Pedranópolis. Município de Pedranópolis, Estado de São Paulo. Relatório Final. IPHAN.

Zanettini Arqueologia. 2010. Mosaico Paulista: guia do patrimônio arqueológico do estado de São Paulo. Zanettini Arqueologia, São Paulo. 